\title{
EFFECT OF RAPID ANNEALINGON MAGNETIC PROPERTIES OF THE NANOCRYSTALLINE Fe ${ }_{80} \mathrm{Nb}_{3} \mathrm{Cu}_{1} \mathrm{Si}_{6} \mathrm{~B}_{10} \mathrm{ALLOY}$
}

\author{
Branislav KUNCA*, Jozef MARCIN*, Peter ŠVEC**, Ivan ŠKORVÁNEK* \\ *Institute of Experimental Physics, Slovak Academy of Sciences, Watsonova 47, 04001 Košice, Slovak Republic \\ e-mail: kunca@saske.sk,marcin@saske.sk,skorvi@saske.sk \\ ${ }^{* *}$ Institute of Physics, Slovak Academy of Sciences, Dúbravská cesta 9, 84511 Bratislava 45, Slovakia, email: peter.svec@savba.sk
}

\begin{abstract}
Impact of rapid annealing on the soft magnetic properties of the $\mathrm{Fe}_{80} \mathrm{Nb}_{3} \mathrm{Cu}_{1} \mathrm{Si}_{6} \mathrm{~B}_{10}$ alloy has been investigated. Parent as-quenched ribbons were prepared by planar flow casting method. Rapid thermal treatments (7-30s) has been conducted at 500 ${ }^{\circ} \mathrm{C}$ using the preheated $\mathrm{Cu}$ blocks to ensure elevated heating rate of more than $100 \mathrm{~K} / \mathrm{s}$. Reference samples were isothermally annealed in the vacuum furnace for $1 \mathrm{~h}$ at the same temperature. X-Ray diffraction unveiled formation of nanocrystalline structure of bcc $\alpha$-Fe(Si) grains, embedded in the residual amorphous matrix in all processed samples, irrespective of the annealing technique. Evolution of coercivity and saturation magnetization values, obtained from the measured hysteresis loops, showed improved magnetic softness of the rapidly annealed samples, compared to the as-quenched and conventionally processed ones. Significant embrittlement of the samples after nanocrystallization has been observed regardless of annealing time and thermal treatment technique used.
\end{abstract}

Keywords: rapid annealing, nanocrystalline alloys, magnetic properties, Fe - based alloys

\section{INTRODUCTION}

Nanocrystalline soft magnetic materials, prepared from melt-spun amorphous precursors, have been a subject of ongoing research of scientists and technologists for past decades [1-3]. Fe-Cu-Nb-Si-B alloys were one of the first to be investigated, as the formation of bcc $\alpha-\mathrm{Fe}(\mathrm{Si})$ grains, with typical size of $10-15 \mathrm{~nm}$, embedded in the residual amorphous matrix enabled to obtain excellent soft magnetic properties [4-5]. Subsequent research and development of new classes of nanocrystalline alloys offered new materials and compositions with enhanced magnetic, thermal or electrical properties. Many of them are suitable for various sensor [6-7], power [8-9] or electronic [10-11] applications such in electric motors, transformer cores or choke coils.

Nanocrystalline structure can be achieved by various processing methods, including thermal treatment for $0.5-1 \mathrm{~h}$ at the temperatures slightly above the onset of primary crystallization temperature [12]. Origin of the improved soft magnetic properties has been described by Herzer's Random Anisotropy Model (RAM) [13]. It states that nanosized structure of ferromagnetic grains leads to negligibly small average crystallographic magnetic anisotropy, and thus enhanced mutual exchange interaction. Studies have shown that significant refinement of the microstructure may be achieved also by short-lasting heat treatment methods with elevated heating rates above $10^{2} \mathrm{~K} / \mathrm{s}$. Various advanced annealing techniques were optimized for such material processing [14-16]. Amongst them, using a pair of preheated $\mathrm{Cu}$ blocks [17-19] showed to be a very promising approach, due to the possibility to achieve good thermal stability, high heating rates, and at the same time prevent undesirable overheating effects [20]. By these means it is possible to obtain improved soft magnetic properties and nanocrystalline microstructure unattainable by conventional annealing techniques [18].

The aim of this paper is to study microstructure, mechanical and magnetic properties of the $\mathrm{Fe}_{80} \mathrm{Nb}_{3} \mathrm{Cu}_{1} \mathrm{Si}_{6} \mathrm{~B}_{10}$ ribbons. Compared to the chemical composition of the conventional $\mathrm{Fe}_{73.5} \mathrm{Cu}_{1} \mathrm{Nb}_{3} \mathrm{Si}_{13.5} \mathrm{~B}_{9}$ FINEMET alloy, non-zero magnetostriction of the studied material will lead to deterioration of its soft magnetic properties, such as coercivity. On the other hand, higher content of the ferromagnetic element $(\mathrm{Fe})$ is expected to give rise to the saturation magnetization. Our interest will focus on the formation of the nanocrystalline structure and possibilities for improvement of the magnetic properties using the rapid annealing technique. Obtained results will be compared with values achieved for the samples conventionally annealed at the same temperature.

\section{SAMPLES AND EXPERIMENTAL METHODS}

Rapidly quenched $\mathrm{Fe}_{80} \mathrm{Nb}_{3} \mathrm{Cu}_{1} \mathrm{Si}_{6} \mathrm{~B}_{10}$ precursor amorphous ribbons with a width of $10 \mathrm{~mm}$ and average thickness of $30 \mu \mathrm{m}$ were produced by planar flow casting. Afterwards, rapid annealing (RA) of the material was conducted by clutching of the specimens between two $\mathrm{Cu}$ blocks preheated at $500{ }^{\circ} \mathrm{C}$ for required annealing time at heating rate estimated to more than $100 \mathrm{~K} / \mathrm{s}$. Samples were wrapped in $\mathrm{Cu}$ foil packets $(\sim 50 \mu \mathrm{m}$ thickness) to provide uniform heating of the sample. Time of annealing was defined as time from the moment of insertion of the packet between the $\mathrm{Cu}$ blocks to its removal. After annealing specimens were immediately cooled down on separate $\mathrm{Cu}$ block held at room temperature. The $\mathrm{Cu}$ blocks were heated using furnace with setpoint temperature stabilized for at least 15 minutes before sample treatment. Reference samples were processed using the conventional isothermal annealing method (CA) under a high vacuum. CA thermal treatment was carried out for $1 \mathrm{~h}$ at $500^{\circ} \mathrm{C}$. Afterwards, specimens were cooled to room temperature at a cooling rate $200^{\circ} \mathrm{C} / \mathrm{h}$. Temperature scans of magnetization were obtained using the vibrating sample magnetometer (VSM) at a constant heating rate of $10 \mathrm{~K} / \mathrm{s}$. During the measurements, a magnetic field of 1000 Oe has been applied in the longitudinal direction of the ribbon. Microstructure of the as-quenched and annealed samples was studied by the X-Ray diffractometry (XRD) with $\mathrm{Cu}$ - 
$\mathrm{K} \alpha$ radiation. Hysteresis loops were measured using the Forster type B-H loop tracer placed in magnetically shielded room. The ductile/brittle behaviour of the asquenched and thermally treated samples was investigated by simple bending tests described by Luborsky and Walter [21]. Specimens have been bent into U-shape between two parallel plates with decreasing separation. Relative strain at fracture can be calculated from their distance at the moment of the sample failure.

\section{RESULTS AND DISCUSSION}

\subsection{Microstructure}

Fig. 1 shows temperature dependence of magnetization of the as-quenched $\mathrm{Fe}_{80} \mathrm{Nb}_{3} \mathrm{Cu}_{1} \mathrm{Si}_{6} \mathrm{~B}_{10}$ alloy. Starting from the room temperature, the first fall of magnetization with increasing temperature corresponds to ferro-paramagnetic transition of the amorphous phase with Curie temperature around $241^{\circ} \mathrm{C}$. This value has been determined as a minimum of the respective derivative of the $\mathrm{M}(\mathrm{T})$ curve (see inset of Fig. 1). Onset of crystallization at $446^{\circ} \mathrm{C}$ indicated by increase of magnetization is related to formation of nanocrystalline grains of bcc $\alpha-\mathrm{Fe}(\mathrm{Si})$ with Curie temperature outside the measurement range. Based on the experimental results as-quenched samples were subsequently exposed to annealing processing at $500^{\circ} \mathrm{C}$.

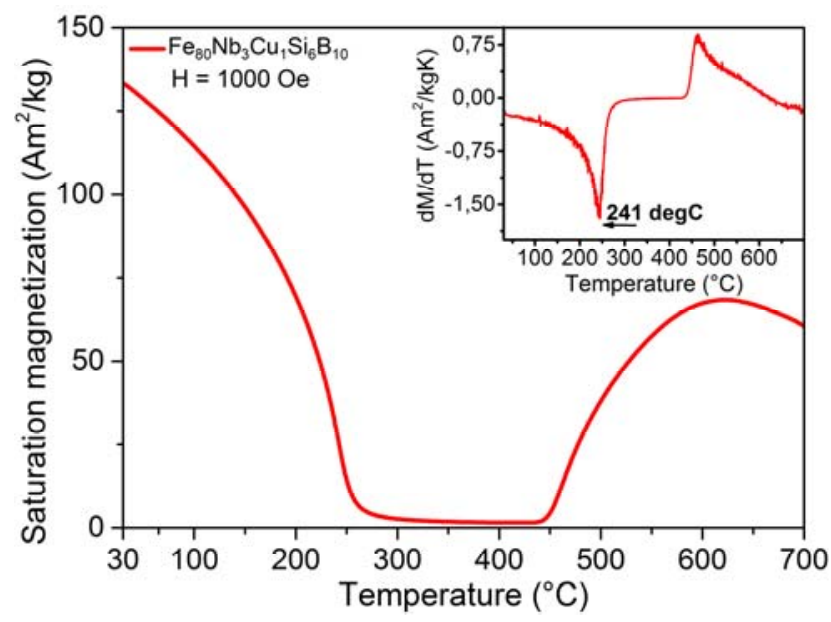

Fig. 1 Temperature dependence of magnetization of the asquenched $\mathrm{Fe}_{80} \mathrm{Nb}_{3} \mathrm{Cu}_{1} \mathrm{Si}_{6} \mathrm{~B}_{10}$. Inset depicts $\mathrm{dM} / \mathrm{dT}$ curve with highlighted Curie temperature of the amorphous phase.

The impact of both thermal processing methods on the microstructure development was examined using the X-ray diffraction (XRD). The XRD patterns of the as-quenched samples (as-q) as well as rapidly (RA) and conventionally (CA) annealed samples are shown in Fig. 2. In case of the precursor sample (black curves), a typical broad pattern is present at around $2 \theta=45^{\circ}$ which is characteristic for an amorphous state. Enhanced intensity of the peak detected for the TOP side at $2 \theta=82.3^{\circ}$ suggests presence of the small amount of textured Fe nanocrystals, preferentially oriented in the (211) direction. Their formation originates probably from lower cooling rate of the TOP side of the sample during melt-spinning production of the parent ribbons. As can be observed from the XRD patterns for the conventionally annealed samples (pink curve), thermal treatment for $1 \mathrm{~h}$ at $500^{\circ} \mathrm{C}$ leads to formation of the nanocrystalline structure of bcc $\alpha-\mathrm{Fe}(\mathrm{Si})$ grains embedded in the residual amorphous matrix. These peaks showed up in diffraction patterns of the rapidly annealed samples as well, indicating that this method induced nanocrystallization process regardless of processing duration.

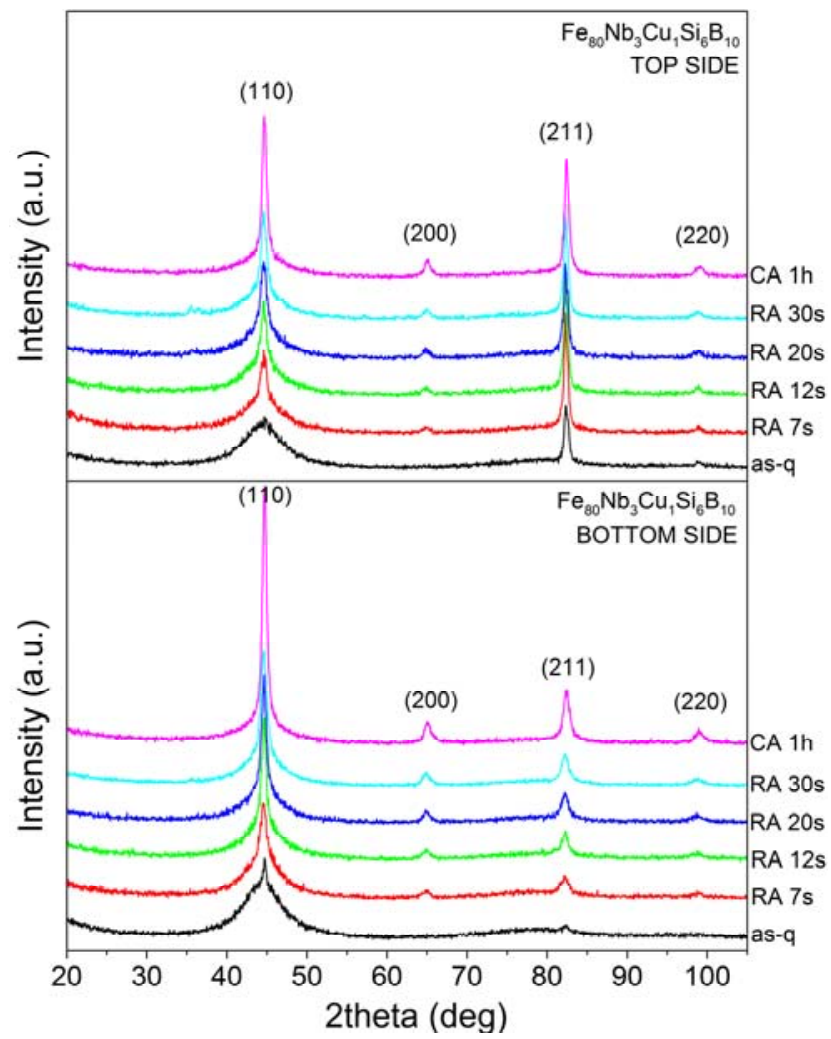

Fig. 2 X-Ray Diffraction patterns from the TOP and BOTTOM side of the as-quenched (as-q) ribbons, as well as rapidly (RA) and conventionally annealed (CA) ribbons at $500^{\circ} \mathrm{C}$ after various processing times.

\subsection{Magnetic properties}

The effect of processing methods on magnetic properties of $\mathrm{Fe}_{80} \mathrm{Nb}_{3} \mathrm{Cu}_{1} \mathrm{Si}_{6} \mathrm{~B}_{10}$ alloy has been investigated via the evolution of the values of saturation magnetization $\left(\mathrm{M}_{\mathrm{s}}\right)$ and coercive field $\left(\mathrm{H}_{\mathrm{c}}\right)$. Both parameters which has been determined from hysteresis loops displayed in the Fig. 3 were measured on $6 \mathrm{~cm}$ long as-quenched as well as annealed ribbons. Rectangular shape of hysteresis loops has been achieved after nanocrystallization of the samples. In Fig. 4 we show the effect of annealing time on the investigated parameters. Saturation magnetization (blue curve) of the nanocrystalline samples is higher compared to the unprocessed specimen, which can be attributed to formation of the bcc $\alpha-\mathrm{Fe}(\mathrm{Si})$ grains. Highest saturation magnetization value $\mathrm{M}_{\mathrm{s}}=155.5 \mathrm{Am}^{2} / \mathrm{kg}$ was achieved after the conventional annealing of the alloy. Rapid annealing resulted in lower values of $\mathrm{M}_{\mathrm{s}}$, although a gradual increase has been observed with increasing annealing time. 30s long rapid thermal treatment yields saturation magnetization of $\mathrm{M}_{\mathrm{s}}=151.6 \mathrm{Am}^{2} / \mathrm{kg}$, making only $2.5 \%$ difference between maximum values obtained after two distinct processing techniques. Coercivity values (red curve) decreased after both rapid and conventional annealing as a result of formation of nanocrystalline structure and stress relaxation. 
Magnetic softening of the studied alloy is more apparent for rapidly annealed samples. $\mathrm{H}_{\mathrm{c}}$ values have ranged between $6.3 \mathrm{~A} / \mathrm{m}$ to $6.9 \mathrm{~A} / \mathrm{m}$, meaning an average drop of coercivity by $44 \%$ as compared to as-quenched sample. Conventional annealing also led to decrease of $\mathrm{H}_{\mathrm{c}}$, however, the obtained value of $9.2 \mathrm{~A} / \mathrm{m}$ is slightly higher compared to the RA ones.

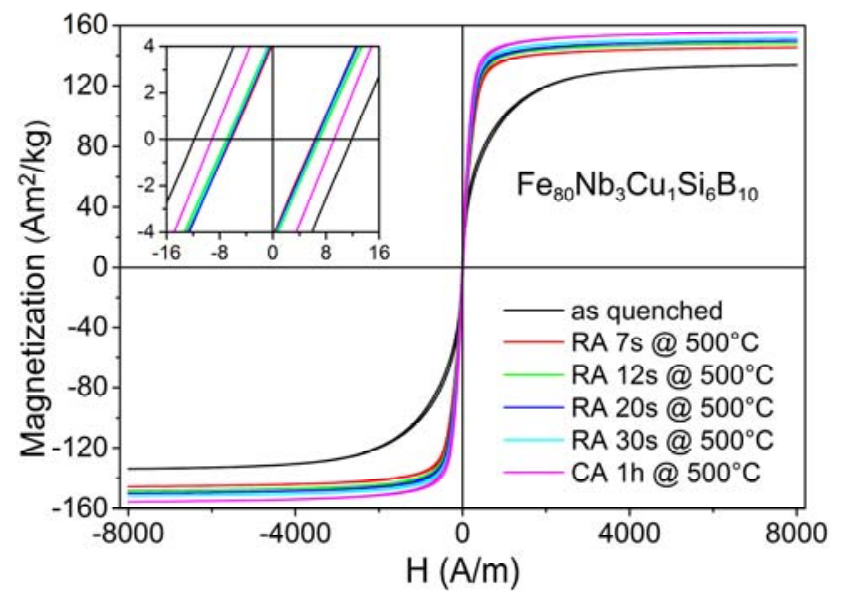

Fig. 3 Hysteresis loops obtained for as-quenched, rapidly annealed (RA) and conventionally annealed (CA) samples.

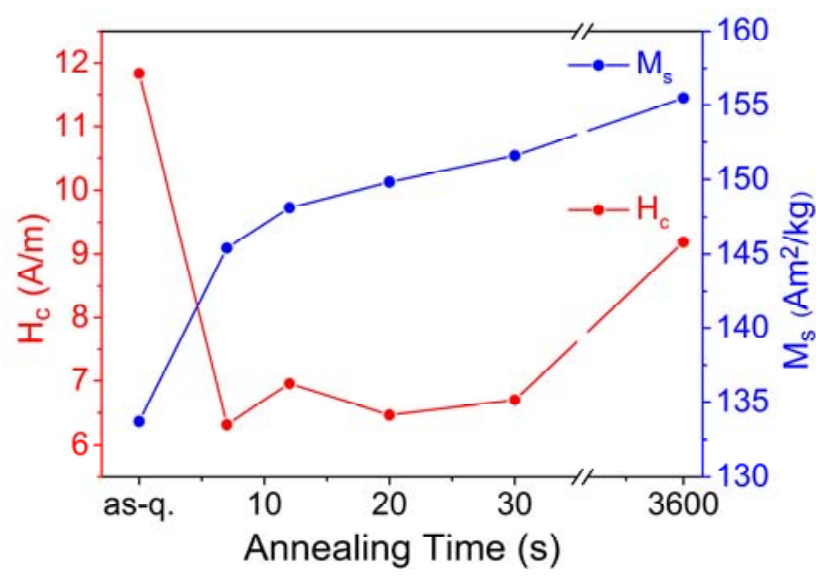

Fig. 4 Evolution of saturation magnetization $\left(\mathrm{M}_{\mathrm{s}}\right)$ and coercive field $\left(\mathrm{H}_{\mathrm{c}}\right)$ values with increasing annealing time.

\subsection{Mechanical properties}

The evolution of brittleness and a ductile behaviour after different thermal processing methods and annealing times is shown in Fig. 5. The fracture strain was determined from simple bending tests as a function of annealing time. 10 samples with length of $10 \mathrm{~mm}$ and width of $3 \mathrm{~mm}$ were used to calculate each point in order to provide enough statistical data. The value of relative strain $\varepsilon_{\mathrm{f}}=1$ which has been observed for the as-quenched amorphous $\mathrm{Fe}_{80} \mathrm{Nb}_{3} \mathrm{Cu}_{1} \mathrm{Si}_{6} \mathrm{~B}_{10}$ ribbons corresponds to fully ductile material with maximum U-bend angle of 180 degrees without fracture or damage. Values $\varepsilon_{\mathrm{f}}<<1$ were calculated for both conventionally and rapidly annealed samples. For $\varepsilon_{\mathrm{f}}<1$, the specimen is prone to break during bend test and the embrittlement of the material increases with decreasing value of $\varepsilon_{\mathrm{f}}$. Clearly, a two phase alloy consisting of nanocrystalline bec $\alpha-\mathrm{Fe}(\mathrm{Si})$ grains embedded in the residual amorphous matrix exhibit low ductility regardless of the amount of crystallinity. This is in good agreement with results obtained for nanocrystalline alloys with similar composition processed above primary crystallization temperature [22].

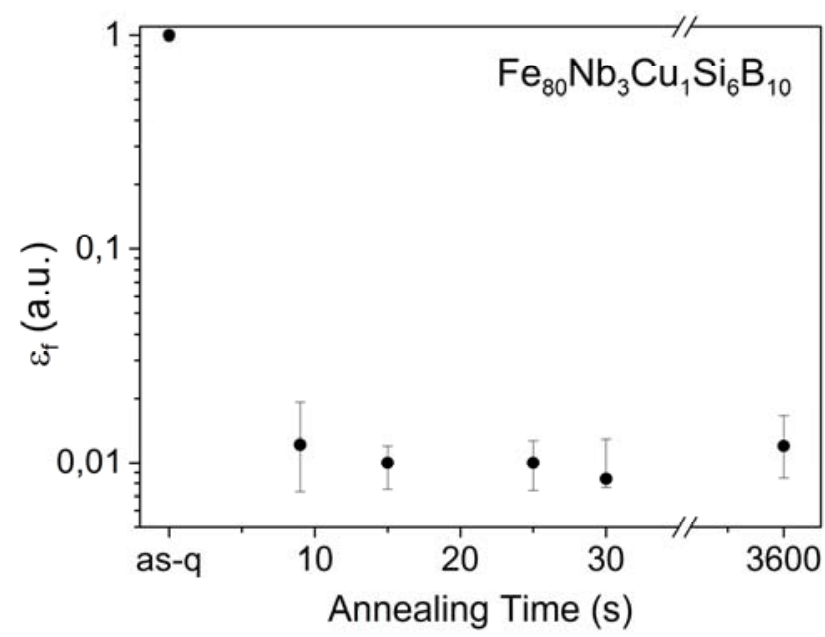

Fig. 5 Relative strain at fracture $\varepsilon$ as a function of annealing time for the as-quenched and nanocrystalline $\mathrm{Fe}{ }_{8} \mathrm{Nb}_{3} \mathrm{Cu}_{1} \mathrm{Si}_{6} \mathrm{~B} 10$ ribbons.

\section{DISCUSSION}

Saturation magnetization has a tendency to rise with annealing time, which is result of increasing volume fraction of the nanocrystalline phase. Its value in the asquenched and annealed samples has been estimated from their temperature scans of magnetization (see Fig. 6). Here, $100 \%$ represents fully developed nanocrystalline structure of the conventionally annealed sample $(\mathrm{t}=3600 \mathrm{~s})$. In case of the FINEMET group of alloys it is around $80 \%$ of the overall volume fraction [23].

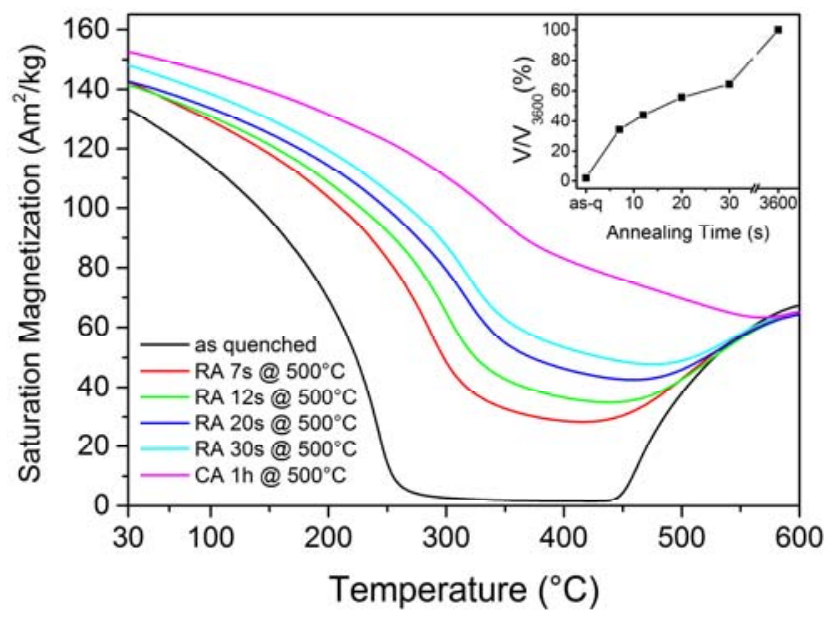

Fig. 6 Temperature scans of magnetization of the as-quenched and annealed $\mathrm{Fe}_{80} \mathrm{Nb}_{3} \mathrm{Cu}_{1} \mathrm{Si}_{16} \mathrm{~B}_{10}$ samples. Inset depicts development of the volume fraction, calculated from the respective $\mathrm{M}(\mathrm{T})$ curves.

Since the nanocrystalline structure of bcc $\alpha-\mathrm{Fe}(\mathrm{Si})$ grains has been detected in all processed samples, low coercivities may be explained in terms of Herzer's Random Anisotropy model (RAM) [13]. Nucleation governed by 
mechanism of $\mathrm{Cu}$ clustering [24] is promoted by high heating rate applied during rapid thermal treatment of the $\mathrm{Fe}_{80} \mathrm{Nb}_{3} \mathrm{Cu}_{1} \mathrm{Si}_{6} \mathrm{~B}_{10}$ alloy. Growth rate of the bec $\alpha-\mathrm{Fe}(\mathrm{Si})$ grains in these specimens is, on the other hand, suppressed as a result of thermal conditions and significantly lower annealing time [22]. Therefore, volume fraction of the nanocrystalline structure in rapidly annealed samples is somewhat lower than that obtained for the conventionally annealed samples. Despite only gradual increase of the volume fraction of the nanocrystalline phase observed in the Fig. 6, coercivity of the rapidly annealed samples does not change significantly, yet saturation magnetization achieves values close to that of conventionally annealed sample. These results shows that rapid annealing technique can be considered as a suitable processing method for improvement of the soft magnetic characteristics in the rapidly quenched FINEMET alloys.

\section{CONCLUSIONS}

Microstructure and magnetic properties were investigated in the conventionally and rapidly annealed $\mathrm{Fe}_{80} \mathrm{Nb}_{3} \mathrm{Cu}_{1} \mathrm{Si}_{6} \mathrm{~B}_{10}$ ribbons. We have shown that rapid thermal processing is a promising tool for tailoring of magnetic characteristics in the nanocrystalline alloys. Both thermal treatment procedures led to formation of bec $\alpha$ $\mathrm{Fe}(\mathrm{Si})$ grains embedded in the residual amorphous matrix. Measurement of the magnetic properties of the processed specimens showed suitability of the rapid annealing technique for achieving low coercivities and saturation magnetization values close to those of the conventionally annealed alloy. No indication for ductility improvement has been shown for the rapidly annealed samples, as compared to the conventionally processed specimens due to formation of similar nanocrystalline structure.

\section{ACKNOWLEDGMENTS}

This work was supported by the projects APVV-150621, VEGA 2/0171/19, ITMS 26110230097 (PhysNet) and JRP SAS-TUBITAK MAGSAT.

\section{REFERENCES}

[1] MAKINO, A. et al.: FeSiBPCu Nanocrystalline Soft Magnetic Alloys with High $\mathrm{B}_{\mathrm{S}}$ of 1.9 Tesla Produced by Crystallizing Hetero-Amorphous Phase, Materials Transactions, Vol. 50, pp. 204-209, Jan. 2009.

[2] ITO, N. et al.: Effect of magnetic field annealing on the soft magnetic properties of nanocrystalline materials, Journal of Magnetism and Magnetic Materials, Vol. 316, is. 2, pp. 458 - 461, Sep. 2007.

[3] SKORVANEK, I. et al.: Improved soft magnetic behavior in field-annealed nanocrystalline Hitperm alloys, Journal of Magnetism and Magnetic Materials, Vol. 304, is. 2, pp. 203 - 207, Sep. 2006.

[4] YOSHIZAWA, Y. - OGUMA, S. - YAMAMUCHI, K.: New Fe-based soft magnetic alloys composed of ultrafine grain structure, Journal of Applied Physics, Vol. 64, is. 10, pp. 6044-6046, Sep. 1988.
[5] HERZER, G.: Anisotropies in soft magnetic nanocrystalline alloys, Journal of Magnetism and Magnetic Materials, Vol. 294, is. 2, pp. 99-106, July 2005.

[6] EGGERS, T. et al.: Impact of the transverse magnetocrystalline anisotropy of a Co coating layer on the magnetoimpedance response of FeNi-rich nanocrystalline ribbon, Journal of Alloys and Compounds, Vol. 741, pp. 1105-1111, Apr. 2018.

[7] GONZÁLEZ-LEGARRETA, L. et al.: Magnetoimpedance effect in nanocrystalline $\mathrm{Fe}_{73.5} \mathrm{Cu}_{1} \mathrm{Nb}_{3} \mathrm{Si}_{13.5} \mathrm{~B}_{9}$ single-layer and bilayer ribbons, Journal of Alloys and Compounds, Vol. 688, pp. 94100, Dec. 2016.

[8] NISHIYAMA, N. - TANIMOTO, K. - MAKINO, A.: Outstanding efficiency in energy conversion for electric motors constructed by nanocrystalline soft magnetic alloy "NANOMET $\AA "$ cores, AIP Advances, Vol. 6, is. 5, No. 055925, Jan. 2016.

[9] BYERLY, K. et al.: Metal amorphous nanocomposite (MANC) alloy cores with spatially tuned permeability for advanced power magnetics applications, The Journal of The Minerals, Metals \& Materials Society, Vol. 70, is. 6, pp. 879-891, Apr. 2018.

[10] NAITOH, Y. et al.: Application of nanocrystalline soft magnetic $\mathrm{Fe}-\mathrm{M}-\mathrm{B}(\mathrm{M}=\mathrm{Zr}, \mathrm{Nb})$ alloys to choke coils, Journal of Applied Physics, Vol. 83, is. 11, pp. $6332-6334$, Oct. 1998.

[11] KIM, G.H. et al:: Magnetic properties of $\mathrm{FeCuNbSiB}$ nanocrystalline alloy powder cores using ball-milled powder, Journal of Applied Physics, Vol. 93, is. 10, pp. 7211 - 7213, May 2003.

[12] MCHENRY, M. E. - WILLARD, M. A. LAUGHLIN D.E.: Amorphous and nanocrystalline materials for applications as soft magnets, Progress in Materials Science, Vol. 44, is. 4, pp. 291-434, Oct. 1999.

[13] HERZER, G.: Grain size dependence of coercivity and permeability in nanocrystalline ferromagnets, IEEE Transactions on Magnetics, Vol. 26, No. 5, pp. 1397-1402, Sep. 1990.

[14] JOHNSON, W. L. et al.: Beating crystallization in glass-forming metals by millisecond heating and processing, Science, Vol. 332, is. 6031, pp. 828-833, May 2011.

[15] HERZER, G. - BUDINSKY, V. - POLAK, CH.: Magnetic properties of $\mathrm{FeCuNbSiB}$ nanocrystallized by flash annealing under high tensile stress, Physica Status Solidi B, Vol. 248, is. 10, pp. 2382-2388, Oct. 2011.

[16] KUHNT, M. et al.: The effect of Co addition on magnetic and structural properties of nanocrystalline (Fe,Co)-Si-B-P-Cu alloys, Journal of Alloys and Compounds, Vol. 766, pp. 686-693, Oct. 2018. 
[17] SUZUKI, K. et al.: Copper-free nanocrystalline soft magnetic materials with high saturation magnetization comparable to that of Si steel, Applied Physics Letters, Vol. 110, is. 1, No. 012407, Dec. 2016.

[18] ZANG, B. et al.: Effect of heating rate during primary crystallization on soft magnetic properties of meltspun Fe-B alloys, Scripta Materialia, Vol. 132, pp. 68-72, Apr. 2017.

[19] MORSDORF L. et al.: Phase selection and nanocrystallization in $\mathrm{Cu}$-free soft magnetic $\mathrm{FeSiNbB}$ amorphous alloy upon rapid annealing, Journal of Applied Physics, Vol. 119, is. 12, No. 124903, Mar. 2016.

[20] PARSONS, R. et al.: Nano-crystallisation and magnetic softening in $\mathrm{Fe}-\mathrm{B}$ binary alloys induced by ultra-rapid heating, Journal of Physics D: Applied Physics, Vol. 51, No. 415001, Sep. 2018.

[21] LUBORSKY, F.E. - WALTER, J.L.: Stability of amorphous metallic alloys, Journal of Applied Physics, Vol. 47, is. 8, pp. 3648-3650, May 1976.

[22] ŠKORVÁNEK, I. - GERLING, R.: The influence of neutron irradiation on the soft magnetic and mechanical properties of amorphous and nanocrystalline $\mathrm{Fe}_{73.5} \mathrm{Cu}_{1} \mathrm{Nb}_{3} \mathrm{Si}_{13.5} \mathrm{~B}$ 9 alloys, Journal of Applied Physics, Vol. 72, is. 8, pp. 3417-3422, May 1992.

[23] HERZER, G.: Soft Magnetic Materials Nanocrystalline Alloys in KRONMÜLLER, H. PARKIN, S.: Handbook of magnetism and advanced magnetic materials, John Wiley \& Sons, Ltd., Hoboken, New Jersey, USA. July 2007.

[24] HONO, K. et al.: $\mathrm{Cu}$ clustering and Si partitioning in the early crystallization stage of an $\mathrm{Fe}_{73.5} \mathrm{Si}_{13.5} \mathrm{~B}_{9} \mathrm{Nb}_{3} \mathrm{Cu}_{1}$ amorphous alloy, Acta Materialia, Vol. 47, is. 3, pp. 997-1006, Feb. 1999.

Received May 6, 2019, accepted June 4, 2019

\section{BIOGRAPHIES}

Branislav Kunca (Ing.) was born in 1993. In 2016 he graduated (Ing.) with distinction at the department of
Physics of the Faculty of Electrical Engineering and Informatics at Technical University in Košice. His master thesis title was "Influence of thermomagnetic treatment on magnetic properties of selected rapidly quenched transition metal based alloys“. Since 2016, he is a PhD student at the Laboratory of Nanomaterials and Applied Magnetism, Institute of Experimental Physics, Slovak Academy of Sciences. His scientific research is focusing on the influence of the thermomagnetic annealing on the magnetic properties of the rapidly quenched soft and hard magnetic alloys.

Jozef Marcin (RNDr, $\mathrm{PhD}$ ) was born in Michalovce, Slovakia in 1971. He graduated from P.J. Safarik University, Kosice in 1996. He received the $\mathrm{PhD}$ degree in Solid State Physics and Acustics at the Faculty of Science of the P.J. Šafarik University in 2003. He is currently an independent researcher of the Nanomaterials and Applied Magnetism Laboratory at the Institute of Experimental Physics, Slovak Academy of Sciences in Košice. His research is focused on the study of magnetic properties of various functional materials such as amorphous and nanocrystalline soft magnetic alloys, permanent magnets, electrical steels and magnetocaloric materials.

Peter Švec (Dipl. Eng, DSc.), born in Bratislava, Slovakia, in 1955, graduated in Solid State Physics from the Faculty of Electrical Engineering, Slovak University of Technology, Bratislava, in 1979, received Ph.D degree in Physics in 1986. Since 1979 he is with the Institute of Physics, Slovak Academy of Sciences, Bratislava, where he is currently a head of Department of Metal Physics. His research field is the physics of metals, recently mainly phase transformations in metal-metalloid glassy systems, soft and hard magnetic amorphous and nanocrystalline materials and their atomically-resolved structure.

Ivan Škorvánek (RNDr, CSc.) was born in Spišská Nová Ves, Slovakia in 1957. He graduated from the Faculty of Science of the P.J. Šafarik University, Košice in 1982 and received his $\mathrm{PhD}$ degree in Condensed Matter Physics from the same University in 1987. He is a head of the Nanomaterials and Applied Magnetism Laboratory at the Institute of Experimental Physics, Slovak Academy of Sciences in Košice. His research interests are focused on structural and magnetic properties of various soft magnetic nanocrystalline, microcrystalline and amorphous alloys, fine magnetic particles, disordered magnetic systems, materials for magnetic refrigeration, multiferroics and magnetic sensors. 